\title{
Referral to rehabilitation in Parkinson's disease: who, when and to what end?
}

\author{
Critérios de encaminhamento para a reabilitação na doença de Parkinson: \\ quem, quando e que finalidade?
}

Josefa Domingos' ${ }^{1}$ Miguel Coelho², Joaquim J Ferreira²

\begin{abstract}
The current state of evidence in non-pharmacological treatments amounts to an impending paradigm shift in neurology where physicians should be alerted that some rehabilitation interventions are already supported in current therapeutic guidelines. This manuscript aims to overview the best scientific data supporting referral to rehabilitation services in order to help physicians make the best use of the existing evidence for non-pharmacological treatments in the different stages of Parkinson's disease.
\end{abstract}

Keywords: Parkinson's disease, non-pharmacological treatments, physical therapy, speech therapy, rehabilitation.

\section{RESUMO}

O atual nível de evidência para tratamentos não farmacológicos sugere uma mudança de paradigma na área da neurologia, a qual passa por alertar os médicos neurologistas de que algumas intervenções na área da reabilitação estão já fundamentadas em linhas de orientação terapêutica. Este trabalho tem o objetivo de rever a melhor evidencia cientifica para a definição de critérios de encaminhamento para serviços de reabilitação, procurando auxiliar os médicos neurologistas a obter o melhor beneficio da evidência cientifica atual para tratamentos não farmacológicos nos diferentes estadios da doença de Parkinson.

Palavras-chave: doença de Parkinson, tratamentos não farmacológicos, fisioterapia, fonoaudiologia, reabilitação.

Parkinson's disease (PD) is a complex heterogeneous neurodegenerative disorder. While many pharmacological treatments in PD have proven beneficial, some motor and nonmotor problems associated with disease progression are not always most comprehensively addressed by a purely pharmacological approach, such as freezing of gait or postural instability The current gold standard drug for symptomatic treatment of motor symptoms of PD, levodopa, has limitations in its use ${ }^{1,2}$ which has justified the need for adjunctive treatment for dopaminergic-responsive symptoms and new treatments for non dopaminergic-related symptoms.

Current PD guidelines already recognize the potential role of some rehabilitation interventions as a mean to improve patients' functionality and to help patients and their families to cope with the disability and functional limitations due to $\mathrm{PD}^{3-6}$. As for example, the Quality Measurement and Reporting Subcommittee of the American Academy of
Neurology recently proposed a set of quality measures for neurology practice ${ }^{7}$ that consider PD rehabilitative therapy options as a quality measure for PD care, recommending it to be addressed by clinicians in clinical practice.

In contrast to these findings, current referral rates to rehabilitation interventions in PD are clearly low ${ }^{8}$. As reported by Nijkrake and colleagues ${ }^{8}$, only $63 \%$ of the PD patients were referred to physical therapy for problems with gait, posture, transfers and balance. For problems with speech, voice, eating and drooling, only $14 \%$ of the patients were referred to speech therapy. For problems related to arm and hand activities, gait, transfers, balance, posture, leisure activities, personal care and domestic/work activities, only $9 \%$ of the PD patients were referred to occupational therapy. Numerous barriers for referral have been discussed in the literature, such as: the degree of the physician's perceived benefit of rehabilitation in PD, the physician's lack of awareness of the recently 
available supportive data, the lack of clear indications for non-pharmacological care and/or the lack of proper time allocated to screen for these referrals ${ }^{8}$.

This justifies the need for a better definition of rigorous, up-dated and feasible medical indications for referral to rehabilitation services interventions that may be applied in an integrated systematic manner and allow better evaluation and monitoring of its true effectiveness in different stages of PD.

We believe that such data needs to be translated into practical and easy to implement recommendations clarifying which patients are appropriate for referral, when referrals should begin and what type of problems should be addressed and for how long. In addition, specific interventions should be identified based on the evidence for efficacy and safety. It is also important to provide clear guidance about what type of improvements should be expected from interventions and how will those gains be expected to be maintained.

Hence, the objective of this short opinion statement was to overview the indications for referral of $\mathrm{PD}$ patients to rehabilitation services based on a review of the recommendations of current published PD international guidelines and published systematic reviews regarding non-pharmacological and non-surgical treatments in PD.

\section{METHOD}

We reviewed the following evidence-based PD recommendations and guidelines: European Federation of Neurological Societies and Movement Disorder Society (EFNS/MDS-ES) ${ }^{3}$, National Institute for Health and Clinical Excellence (NICE) ${ }^{4}$, American Academy of Neurology (AAN) ${ }^{5}$ and Movement Disorder Society (MDS) ${ }^{6}$, concerning non-pharmacological and non-surgical interventions. These were believed to offer an exhaustive, synthetic and up-to-date analysis of the level of evidence of all treatments proposed for PD. As a second step, we reviewed published Cochrane Collaboration and other systematic reviews and other key clinical studies focusing on the effectiveness of similar interventions in PD. Based on the level of evidence and grade of recommendations supporting the different rehabilitation interventions, we then outlined potential medical referral indications. In order to support which patients are more appropriate for referral, we structured potential medical referral indications based on a disease-specific problem for which there is some evidence that these may have some benefit with non-pharmacological treatments, and, thus, with a relative contribution to the appropriateness of referral.

\section{RESULTS}

The non-pharmacological treatment interventions most frequently highlighted in all PD guidelines are provided by physical therapists, speech-language therapists, PD nurse specialists and occupational therapists (Table 1). In Tables 2 and 3 we show the referral indications for non-pharmacological and non-surgical therapies, based on specific disease problems in PD. We chose 7 motor problem domains (transfers, gait, physical capacity, postural instability, falls, freezing and speech) and 7 non-motor problem domains (orthostatic hypotension, urinary disturbance, gastrointestinal motility dysphagia, drooling, sleep disorders, and pain) as indications for referral.

From the data analyzed in our review it is possible to conclude that there is: 1) consistent data supporting physical therapy referral and use in PD for transfers and mobility problems, gait disturbances, balance, falls and freezing; and 2) a possible beneficial role of speech therapy for vocal intensity, phonation and dysphagia.

Given the problem-based distribution of the evidence, it is important to note that even though not included in the table, there is some evidence for the benefit of a PD nurse specialist for general counselling and palliative care ${ }^{9}$ and there is insufficient data to conclude on the role of occupational therapy and complementary therapies. Additionally, there is also a small amount of consensual general measures existing for most non-motor problems in PD and no strong data on rehabilitation interventions for parkinsonism and motor complications.

\section{Translation of evidence-based data to clinical practice}

Increased clinicians awareness about the benefits of rehabilitation and initiatives to overcome barriers to referral are critical to improve the quality of care of people with PD.

Table 1. Summary of non-pharmacological therapies outlined in the reviewed guidelines.

\begin{tabular}{l} 
Non-pharmacological therapies \\
\hline Main key therapies \\
Nurse PD specialist \\
Physical therapy \\
Speech and language therapy \\
Occupational therapy \\
\hline Others \\
Dietician \\
Social worker \\
Sexologist \\
Psychologist \\
Complementary therapies such as: Tai Chi, Quigong, Massage, \\
Acupuncture and Nutritional supplements. \\
Hydrotherapist \\
Psychiatrist \\
Music Therapist \\
Patient Associations
\end{tabular}


Adequate screening and selection of these patients for non pharmacological treatments may increase the benefits of these treatments, and reduce unnecessary procedures and unrealistic expectations in patients with a less favourable profile. Given the practical limitations in a general neurological setting, we faced the challenge to translate the existing evidence into concise and easily applicable referral indications, embedded in a user-friendly referral support tool (Table 2 and 3 ).

We now address below 3 important questions regarding referral of patients to rehabilitation interventions:

Table 2. Summary of suggested non-pharmacological, non-surgical referral indications based on specific motor problem/ impairment domains in Parkinson's disease.

\begin{tabular}{|c|c|c|c|}
\hline \multicolumn{4}{|c|}{ Motor problems } \\
\hline Problem domain & Treatment interventions & $\begin{array}{c}\text { Guidelines and level of } \\
\text { evidence }\end{array}$ & Implications for referral \\
\hline \multirow[t]{6}{*}{$\begin{array}{l}\text { Transfers } \\
\text { \& Mobility Problems }\end{array}$} & Strategy training with cueing. & $\begin{array}{l}\text { KNGF [11] - Level II } \\
\text { MDS [6] - Level II }\end{array}$ & \multirow{6}{*}{$\begin{array}{l}\text { Physical therapy should be } \\
\text { considered to address motor } \\
\text { impairments in transfers \& mobility. }\end{array}$} \\
\hline & $\begin{array}{l}\text { Cognitive movement strategy training } \\
\text { for daily activities and transfers. }\end{array}$ & KNGF [11] - Level II & \\
\hline & Movement initiation training. & NICE [4] - Level II & \\
\hline & $\begin{array}{c}\text { Training functional independence, } \\
\text { including mobility and activities of daily } \\
\text { living. }\end{array}$ & NICE [4] - Level II & \\
\hline & Alexandre Technique. & NICE [4] - Level III & \\
\hline & $\begin{array}{c}\text { Advice regarding safety in the home } \\
\text { environment. }\end{array}$ & NICE [4] - Level II & \\
\hline \multirow[t]{2}{*}{ Gait disturbances } & $\begin{array}{l}\text { Gait re-education. } \\
\text { Cued training and strategies. } \\
\text { Cued training for dual task. }\end{array}$ & $\begin{array}{l}\text { NICE [4] - Level II } \\
\text { EFNS/MDS [3] - Level II } \\
\text { EFNS/ MDS [3] - Level III }\end{array}$ & \multirow{4}{*}{$\begin{array}{l}\text { Physical therapy should be } \\
\text { considered to address motor } \\
\text { impairments in balance, gait, } \\
\text { physical capacity, falls and freezing. } \\
\text { Tai chi and Qigong may be considered } \\
\text { for balance and gait impairments. }\end{array}$} \\
\hline & $\begin{array}{l}\text { Treadmill training for gait speed. } \\
\text { Exercise - based interventions. }\end{array}$ & $\begin{array}{l}\text { EFNS/ MDS [3] - Level II } \\
\text { EFNS/ MDS [3] - Level II }\end{array}$ & \\
\hline \multirow[t]{2}{*}{ Physical capacity } & Aerobic exercise. & NICE [4] - Level II & \\
\hline & & EFNS/MDS [3] - Level II & \\
\hline \multirow{6}{*}{$\begin{array}{l}\text { Postural instability and } \\
\text { balance problems }\end{array}$} & Treadmill training. & MDS [6] - Level II & \\
\hline & & EFNS/ MDS [3] - Level II & \\
\hline & Physical activity and exercise. & MDS [6] - Level II & \\
\hline & & EFNS/MDS [3] - Level II & \\
\hline & Balance training. & NICE [4] - Level II & \\
\hline & Tai Chi or Qigong. & EFNS/MDS [3] - Level II & \\
\hline \multirow[t]{5}{*}{ Falls and fear of falling } & General elderly recommendations. & EFNS/ MDS [3] - Level IV & \\
\hline & Physical activity and exercise for near & MDS [6] - Level II & \\
\hline & falls. & EFNS/MDS [3] - Level II & \\
\hline & Physical activity and exercise for falls. & MDS [6] - Level III & \\
\hline & & EFNS/MDS [3] - Level II & \\
\hline \multirow[t]{5}{*}{ Freezing } & Cueing training in the home. & $\begin{array}{c}\text { MDS [6] - Level II } \\
\text { EFNS/ MDS [3] - Level II }\end{array}$ & \multirow{5}{*}{$\begin{array}{l}\text { Physical therapy should be } \\
\text { considered for cueing training for } \\
\text { freezing. }\end{array}$} \\
\hline & Visual or auditory cues & MDS [6] - Level III & \\
\hline & & EFNS/ MDS [3] - Level III & \\
\hline & Combining treadmill training and & MDS [6] - Level II & \\
\hline & cueing. & EFNS/ MDS [3] - Level II & \\
\hline \multirow[t]{7}{*}{ Speech impairment } & Lee Silverman Voice Therapy (LSVT). & NICE [4] - Level II & \multirow{7}{*}{$\begin{array}{l}\text { Speech therapy using LSVT may } \\
\text { be considered to address motor } \\
\text { complications regarding vocal } \\
\text { intensity and phonation of speech. }\end{array}$} \\
\hline & & MDS [6] - Level II & \\
\hline & & EFNS/ MDS [3] - Level II & \\
\hline & Pitch Limiting Voice Treatment (PLVT) & MDS [6] - Level IV & \\
\hline & & EFNS/ MDS [3] - Level IV & \\
\hline & $\begin{array}{l}\text { Teaching strategies to optimise speech } \\
\text { intelligibility. }\end{array}$ & NICE [4] - Level IV & \\
\hline & Use of assistive technologies. & NICE [4] - Level IV & \\
\hline
\end{tabular}

The evidence was graded according to original source. However, to facilitate interpretation and comparison we convert NICE guideline recommendations to level of evidence, based on the following:Class A=Level I;Class B=Level II; Class C=Level III;Class D (GPP)=Level IV. Abbreviations: EFNS/MDS-ES, European Federation of Neurological Societies and Movement Disorder Society; NICE, National Institute for Health and Clinical Excellence; MDS, Movement Disorder Society. 
Table 3. Summary of suggested non-pharmacological, non-surgical referral indications based on specific non-motor problem/ impairment domains in Parkinson's disease.

\begin{tabular}{|c|c|c|c|}
\hline \multicolumn{4}{|c|}{ Non motor problems } \\
\hline Problem domain & Treatment interventions & $\begin{array}{c}\text { Guidelines and level of } \\
\text { evidence }\end{array}$ & Implications for referral \\
\hline $\begin{array}{l}\text { Orthostatic } \\
\text { hypotension }\end{array}$ & General recommendations. & $\begin{array}{c}\text { MDS [6] - Level IV } \\
\text { EFNS/ MDS [3] - Level IV }\end{array}$ & \multirow{3}{*}{$\begin{array}{c}\text { General measures may be addressed } \\
\text { by any of the multidisciplinary team } \\
\text { members for non-motor problems such } \\
\text { as orthostatic hypotension, nocturia, } \\
\text { constipation, daytime somnolence, REM } \\
\text { sleep behaviour disorder and good sleep } \\
\text { hygiene. }\end{array}$} \\
\hline Urinary disturbance & General measures for treating nocturia. & $\begin{array}{c}\text { MDS [6] - Level IV } \\
\text { EFNS/ MDS [3] - Level IV }\end{array}$ & \\
\hline $\begin{array}{l}\text { Gastrointestinal } \\
\text { motility }\end{array}$ & $\begin{array}{l}\text { General recommendations for } \\
\text { constipation. }\end{array}$ & $\begin{array}{c}\text { MDS [6] - Level IV } \\
\text { EFNS/ MDS [3] - Level IV }\end{array}$ & \\
\hline \multirow[t]{3}{*}{ Dysphagia } & $\begin{array}{l}\text { Speech therapy for assessment, } \\
\text { swallowing advice and further } \\
\text { instrumental investigations. }\end{array}$ & MDS [6] - Level IV & \multirow[t]{4}{*}{$\begin{array}{l}\text { Speech therapy for assessment and } \\
\text { swallowing advice may be considered for } \\
\text { dysphasia and drooling. }\end{array}$} \\
\hline & Advice on modification of food/drink. & EFNS/ MDS [3] - Level IV & \\
\hline & $\begin{array}{l}\text { Management to support safety and } \\
\text { efficiency of swallowing and minimize } \\
\text { risk of aspiration. }\end{array}$ & NICE [4] - Level IV & \\
\hline $\begin{array}{l}\text { Excessive saliva and } \\
\text { drooling }\end{array}$ & Behavioral management techniques. & NICE [4] - Level IV & \\
\hline \multirow[t]{3}{*}{ Sleep disorders } & $\begin{array}{l}\text { General measures for treatment of } \\
\text { daytime somnolence in PD. }\end{array}$ & $\begin{array}{l}\text { NICE [4] - Level IV } \\
\text { MDS [6] - Level IV }\end{array}$ & \multirow{4}{*}{$\begin{array}{c}\text { General measures may be addressed } \\
\text { by any of the multidisciplinary team } \\
\text { members for non-motor problems such } \\
\text { as daytime somnolence, REM sleep } \\
\text { behaviour disorder, good sleep hygiene } \\
\text { and pain. }\end{array}$} \\
\hline & $\begin{array}{l}\text { In REM sleep behaviour disorder in PD, } \\
\text { methods of self-protection. }\end{array}$ & MDS [6] - Level IV & \\
\hline & Good sleep hygiene. & $\begin{array}{l}\text { NICE [4] - Level IV } \\
\text { MDS [6] - Level IV }\end{array}$ & \\
\hline Pain & Generic management. & NICE [4] - Level IV & \\
\hline
\end{tabular}

The evidence was graded according to original source. However, to facilitate interpretation and comparison we convert NICE guideline recommendations to level of evidence, based on the following: Class A=Level I; Class B=Level II; Class C=Level III; Class D (GPP)=Level IV. Abbreviations: EFNS/MDS-ES, European Federation of Neurological Societies and Movement Disorder Society; NICE, National Institute for Health and Clinical Excellence; MDS, Movement Disorder Society.

\section{Which patients to refer?}

Here we argue that a rationale that allows us to answer the question which patients to refer should be based on the symptom or problem the patient has and the effectiveness of the alternative treatments for that specific problem.

Hence, according to the specific disease problems, people with PD that experience problems with transfers, posture, reaching and grasping, gait, freezing, falls and physical capacity should be referred to a physiotherapist. This is in line with current practice recommendations supported in a recent evidence-based analysis of physical therapy in $\mathrm{PD}^{10}$ and two specific physical therapy PD guidelines ${ }^{11,12}$. People with PD that experience problems in vocal intensity, phonation and dysphagia may be referred to a speech therapist. Additionally, with less supporting evidence, people with PD that experience balance and gait impairments may benefit from Tai Chi and Qigong ${ }^{3}$.

It is important to recognize that the evidence in all current guidelines regarding non-pharmacological, non surgical treatments supporting the interventions applied to each impairment differ broadly and are limited, in large part due to the methodological flaws of the available studies. This makes it difficult to interpret and conclude on the specific characterization of each problem and which patients respond better to a given treatment.
Additionally, the severity of cognitive impairment may have a negative impact on the appropriateness of referral. One may believe that patients who exhibit cognitive impairment may be less favourable due to a decreased ability to cooperate with the treatment. Conversely, they are usually excluded from research studies ${ }^{13}$ and so current findings can not yet be generalised to these patients.

\section{When to refer?}

Concerning early stages of the disease, according to the physical therapy international guideline ${ }^{11}$, physical therapy is the only non-pharmacological treatment intervention that explicitly recommends that standard medical care should be complemented with early referral to physiotherapy services in the early to intermediate stages of PD. However, it is not clear for what specific problem and with what expected outcome.

Most studies focus on patients in intermediate stages of the disease (stages II and III on the Hoehn and Yahr Scale). For example, daily activities and transfers were shown to improve with movement strategy training using external and cognitive cues in a 2-week inpatient rehabilitation program ${ }^{14}$ with 33 PD patients in stage II or III Hoehn and Yahr, declining after 3 months without training after discharge. Combining strength, gait, treadmill and relaxation in a six week group physical therapy was also shown to induce 
changes in UPDRS-III, Sickness Impact Profile and timed comfortable walking speed in a single-blind, cross-over, RCT in 68 PD patients in stage II or III Hoehn and Yahr ${ }^{15}$. Similar beneficial changes in UPDRS-III were obtained in a physical therapy program named BIG with a four week individual training of large amplitude movements in 60 patients in I to III Hoehn and Yahr ${ }^{16}$.

Difficulty in mobility activities, gait disturbances, postural instability, freezing, falls and speech impairment emerge as disease progresses and occur mainly in advanced stages of $\mathrm{PD}^{17}$. This stage is commonly defined as stages 4 and 5 on the Hoehn and Yahr scale, which corresponds to loss of physical independence ${ }^{18}$. Thus, it is reasonable to believe that referral for physiotherapy interventions would largely be focused in this advanced PD stage. Interestingly, most rehabilitation clinical trials generally exclude patients in this advanced PD stage with a mean upper age limit for exclusion of 79.3 years $^{19}$. Indeed, to our knowledge, there are no RCTs that have objectively assessed the efficacy and safety of these non-pharmacological treatments in advanced stages PD. It has only been reported that referral to a nurse specialist may be beneficial in particular in the palliative stage for management of drugs, pressure ulcer risk and ongoing education ${ }^{4}$. This limits the amount and quality of data for referral on current non pharmacological interventions for motor and non motor problems in PD in this stage. It also limits the application of our proposed referral indications to advanced stages PD and, thus, should be considered with care.

\section{To what end?}

The specific therapeutic interventions outlined in the guidelines are briefly summarized in Table 2 and 3. Importantly, there is a common perception that none of the currently available therapeutic interventions, alone or combined with other interventions, offers an entirely satisfying strategy for managing PD because patients suffer from multiple problems. However, regarding rehabilitation interventions, they usually require compatible and even similar therapeutic interventions (Figure). Consequently, the combination of these therapeutic interventions outlined in the literature should be evaluated. It is necessary to see if and how the interventions are related or interplay and then try developing a referral treatment approach that combines interventions based on a solid rationale of the interplay of their true effectiveness, safety and health care contexts and costs.

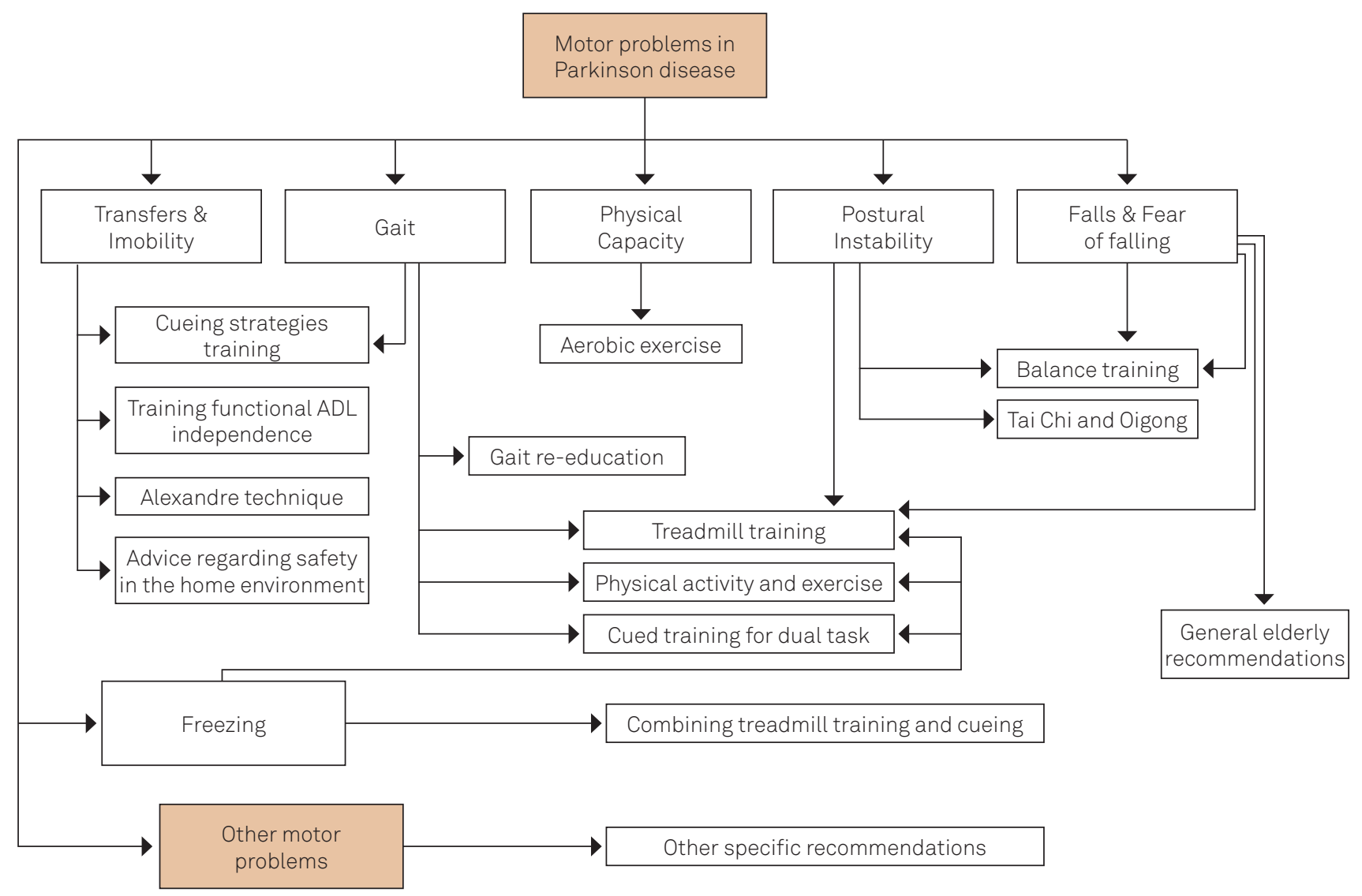

Figure. Intersection of non-pharmacological treatment interventions for Parkinson's disease. Some motor problems may have similar therapeutic interventions. For example, treadmill training may be used for problems such as gait, freezing, postural instability and fear of falling. The combination of these therapeutic interventions may allow us to see how the interventions are related or interplay and ultimately facilitate the referral treatment approach. 
Safety issues should also be considered for referral. Ideally, there should be a balance between efficacy, safety and usefulness of a given intervention in order to be considered clinically useful and recommend for referral. However, regarding safety it has only been reported concerns on potential adverse effects of cueing-based gait training but it was shown not to increase the risk of falling ${ }^{20}$. Similarly, there has also been concerns of the possible adverse effects of nutritional supplements and its influence on antiparkinsonian medication $^{3}$. Additionally, the EFNS/MDS-ES guidelines ${ }^{3}$ highlights that the degree of specific expertise among physical therapists allows better intervention on issues of safety and prevention of falls/injuries while promoting mobility and maintaining optimal levels of physical activity ${ }^{10,13}$.

\section{Implications for clinical practice}

Addressing non-pharmacological interventions and their potential use on daily routine should be a standard part of the medical treatment of patients with PD. According to included guidelines/recommendations and systematic reviews, at this time, there is enough evidence for physicians to refer or recommend physical therapy, some evidence for speech, less for a PD nurse specialist, and no evidence for occupational therapy.

\section{Implications for clinical research}

More strong clinical data supporting the real efficacy and safety of non-pharmacological interventions in all stages PD remains an unmet need. The combination of these treatments and their application in an integrated and systematic manner is also of interest for future studies.

In addition, variation in rehabilitation referral may be indicative of problems with access and/or inappropriate referral. An understanding of the factors that affect physician/ neurologist referral to rehabilitation is important because of the influence referrals can have on the costs and quality of medical care. There is also a strong need for long term analysis of these interventions on motor and non-motor problems with well designed RCTs in order to allow us to conclude on true efficacy, on the optimal timing, on safety and on stage for referral.

\section{References}

1. Hely MA, Morris JG, Reid WG, Trafficante R. Sydney Multicenter Study of Parkinson's disease: non-L-dopa-responsive problems dominate at 15 years. Mov Disord 2005;20:190-199.

2. Hely MA, Reid WG, Adena MA, Halliday GM, Morris JG. The Sydney multicenter study of Parkinson's disease: the inevitability of dementia at 20 years. Mov Disord 2008;23:837-844.

3. OertelWH, Berardelli A, Bloem BR, et al. Late (complicated) Parkinson's disease. In: Gilhus BaB (Ed). European Handbook of Neurological Management: Blackwell Publishing Ltd 2nd edition; 2011:237-255.

4. Clarke C, Sullivan T, A. Mason, et al. National clinical guideline for diagnosis and management in primary and secondary care. In: London RCoP (Ed). National Collaborating Centre for Chronic Conditions Parkinson's disease; 2006.

5. Zesiewicz TA, Sullivan KL, Arnulf I, et al. Practice parameter: treatment of nonmotor symptoms of Parkinson disease: report of the quality standards subcommittee of the American Academy of Neurology. Neurology 2010;74:924-931.

6. Goetz CG, Poewe W, Rascol O, Sampaio C. Evidence-based medical review update: pharmacological and surgical treatments of Parkinson's disease: 2001 to 2004. Mov Disord 2005;20:523-539.

7. Cheng EM, Tonn S, Swain-Eng R, Factor SA, Weiner WJ, Bever CT Jr. Quality improvement in neurology: AAN Parkinson disease quality measures: report of the Quality Measurement and Reporting Subcommittee of the American Academy of Neurology. Neurology 2010;75:2021-2027.

8. Nijkrake MJ, Keus SH, Oostendorp RA, et al. Allied health care in Parkinson's disease: referral, consultation, and professional expertise. Mov Disord 2009;24: 282-286.

9. Hagell P. Nursing and multidisciplinary interventions for Parkinson's disease: what is the evidence? Parkinsonism Relat Disord 2007; 13(Suppl 3):S501-S508.

10. Keus SH, Bloem BR, Hendriks EJ, Bredero-Cohen AB, Munneke M. Evidence-based analysis of physical therapy in Parkinson's disease with recommendations for practice and research. Mov Disord 2007;22:451-460.

11. Keus SHJ, Hendriks HJM, Bloem B.R., et al. KNGF Guidelines for physiotherapy in patients with Parkinson's Disease. Ned Tijdschr Fysiother 2004.

12. Plant R, Walton G, Ashburn A, Lovgreen B, Handford F, Kinnear E. Guidelines for physiotherapy practice in Parkinson's disease. Newcastle, U.K: University of Northumbria, Institute of rehabilitation 2001.

13. Keus SH, Munneke M, Nijkrake MJ, Kwakkel G, Bloem BR. Physical therapy in Parkinson's disease: evolution and future challenges. Mov Disord 2009; 24:1-14.

14. Morris ME, lansek R, Kirkwood B. A randomized controlled trial of movement strategies compared with exercise for people with Parkinson's disease. Mov Disord 2009;24:64-71.

15. Ellis T, de Goede CJ, Feldman RG, Wolters EC, Kwakkel G, Wagenaar RC. Efficacy of a physical therapy program in patients with Parkinson's disease: a randomized controlled trial. Arch Phys Med Rehabil 2005;86:626-632.

16. Ebersbach G, Ebersbach A, Edler D, et al. Comparing exercise in Parkinson's disease-the Berlin LSVT(R)BIG study. Mov Disord 2010;25:1902-1908.

17. Coelho M, Marti MJ, Tolosa E, et al. Late-stage Parkinson's disease: the Barcelona and Lisbon cohort. J Neurol 2010;257:1524-1532.

18. Goetz CG, Poewe W, Pascol O, et al. Movement Disorder Society Task Force report on the Hoehn and Yahr staging scale: status and recommendations. Mov Disord 2004;19:1020-1028.

19. Fitzsimmons PR, Blayney S, Mina-Corkill S, Scott GO. Older participants are frequently excluded from Parkinson's disease research. Parkinsonism and Related Disorders 2012;18:585-589.

20. Nieuwboer A, Kwakkel G, Rochester L, et al. Cueing training in the home improves gait-related mobility in Parkinson's disease: the RESCUE trial.J Neurol Neurosurg Psychiatry 2007;78:134-140. 